\title{
Cerebral oedema: Pathophysiological mechanisms and experimental therapies
}

\author{
Shalvi Mahajan, Hemant Bhagat
}

\section{INTRODUCTION}

Cerebral oedema per se is not a disease entity. It is a clinico-pathological state that is characterised by an increase in brain water content (above the normal brain water content of approximately $80 \%$ ). It usually occurs in response to brain insult which is seen in a variety of neurological and non-neurological conditions. Cerebral oedema increases brain volume. Because brain is confined within rigid skull, increase in brain water content ultimately results in raised intracranial pressure (ICP). Raised ICP decreases cerebral perfusion pressure leading to cerebral ischemia. In addition, cerebral oedema may result in brain herniation due to the associated mass effect. Management of cerebral oedema is a great challenge for both the neurosurgeons and neuroanaesthetists as current treatment modalities are largely symptomatic. They range from general measures to osmotherapy, barbiturate coma, steroids and decompressive craniectomy. Though oedema-targeted therapies are being specifically designed, they remain more or less as experimental models.

\section{HISTORY}

Cerebral oedema and brain oedema both are similar entities. However, brain oedema is commonly confused with brain swelling. Therefore, Reichardt used the term brain oedema to differentiate these two pathological conditions ${ }^{[1]}$ Brain swelling was believed to originate from cerebral vascular engorgement. Pappius (1974) defined brain oedema as net increase in brain water content which leads to an increase in tissue volume. Traditionally, cerebral oedema was divided into two groups by Klatzo.

Department of Anaesthesia and Intensive Care, Division of Neuroanaesthesia, PGIMER, Chandigarh, India

\begin{tabular}{|l|l|}
\hline \multicolumn{2}{|c|}{ Access this article online } \\
\hline Quick Response Code: & Website: \\
\hline & www.jnaccjournal.org \\
\cline { 2 - 2 } & \\
\hline
\end{tabular}

He used a 'cold injury' model to describe the cytotoxic or vasogenic oedema related to cellular injury or blood brain barrier (BBB) breakdown, respectively. ${ }^{[2]}$ Later, Fishman added third type as 'interstitial oedema' which is commonly associated with hydrocephalus. ${ }^{[3]}$

\section{CLASSIFICATION}

Cerebral oedema can be classified into the following types:

- Vasogenic oedema

- Cytotoxic/ionic/cellular oedema

- Interstitial/hydrocephalic oedema

- Osmotic/hypostatic oedema

- Hydrostatic oedema.

Although most of the times brain insult involve an overlap of different types of cerebral oedema, one type can predominate over other depending on the type and duration of brain injury.

\section{PATHOPHYSIOLOGY}

The pathophysiology of cerebral oedema is complex [Figure 1]. Irrespective of the underlying cause, cascade of events initiate at molecular level which results in the accumulation of fluid in the brain's intracellular and extracellular spaces. There are four fluid compartments in the brain-blood (cerebral vessels), cerebrospinal fluid (CSF) (ventricular system), interstitial fluid (brain parenchyma) and intracellular fluid (neurons and glial cells). These compartments are interlinked and under normal physiological conditions, there is tight control of movement of fluid and solute particles from one compartment to other.

This is an open access article distributed under the terms of the Creative Commons Attribution-NonCommercial-ShareAlike 3.0 License, which allows others to remix, tweak, and build upon the work non-commercially, as long as the author is credited and the new creations are licensed under the identical terms.

For reprints contact: reprints@medknow.com

How to cite this article: Mahajan S, Bhagat $\mathrm{H}$. Cerebral oedema: Pathophysiological mechanisms and experimental therapies. J Neuroanaesthesiol Crit Care 2016;3:22-8. 


\section{Vasogenic oedema}

This is the most common form of cerebral oedema and it is primarily due to the breakdown of BBB secondary to mechanical disruption (brain trauma, acute malignant hypertension, radiation) or chemical mediators (tumours, inflammation and infection).

BBB consists of endothelial cells, basement membrane and foot processes of astrocytes. Cerebral endothelial cells have two unique features - presence of tight junctions along inter endothelial region (which limit movement of plasma protein and compounds with molecular weight - 60,000 and high) and fewer caveolae (plasmalemmal vesicles which either by fluid-phase transcytosis or transendothelial channels allow protein passage).$^{[4]}$ Initially, during BBB injury, there is an increase in caveolae and later tight junction breakdown followed by endothelial cell injury. During BBB injury, there is an activation of glial cells. Activated glial cells produce various mediators such as bradykinin, serotonin, histamine, complement, arachidonic acid, nitric oxide and leucotrienes. Thus, BBB injury results in the movement of protein rich exudates into extracellular space. ${ }^{[5]}$ In this type of oedema, white matter is more affected (low cell density, multiple parallel axonal tracts and loose extracellular fluid) as compared to grey matter (high cell density and multiple interconnected axonal tracts).

\section{Cytotoxic oedema}

This is also known as cellular or ionic oedema where BBB is intact. Basis of cytotoxic oedema is, 'Cellular energy failure with disrupted ionic pump with anaerobic metabolism' which is either due to hypoxia or ischaemia. ${ }^{[6]}$ It is commonly seen after acute arterial infarction and lacunar infarcts. During cerebral ischaemia, there is cessation of blood flow either complete or partial leading to disturbance of Na-K-ATPase pump which is responsible for pumping sodium and potassium into extracellular and intracellular compartment, respectively $\left(3 \mathrm{Na}^{+}: 2 \mathrm{~K}^{+}\right)$. To understand the pathogenesis of cytotoxic oedema, various models such as ischaemic models (focal and global) and water intoxication model have been described. ${ }^{[7]}$ The best among them is the focal ischaemic model, which is being discussed here. Focal ischaemic model describes cessation of blood flow to brain. When blood flow decreases to $<20 \mathrm{ml} / \mathrm{min} / 100 \mathrm{~g}$, there is failure of ATP dependent ionic pump. Within seconds of pump failure, $\mathrm{Na}^{+}$ions get accumulated into intracellular compartment followed by inward water movement to maintain iso-osmotic state. In addition, $\mathrm{Na}^{+}$ions are accompanied by inward flow of $\mathrm{Ca}^{+}, \mathrm{H}^{+}$, $\mathrm{HCO}_{3}{ }^{-}$ions and outward flow of $\mathrm{K}^{+}$ions. These changes are reversible if blood is immediately restored within 3-4 min. Beyond $6 \mathrm{~min}$ of ischaemia, irreversible injury occurs with ischaemic core formation. Ischaemic core

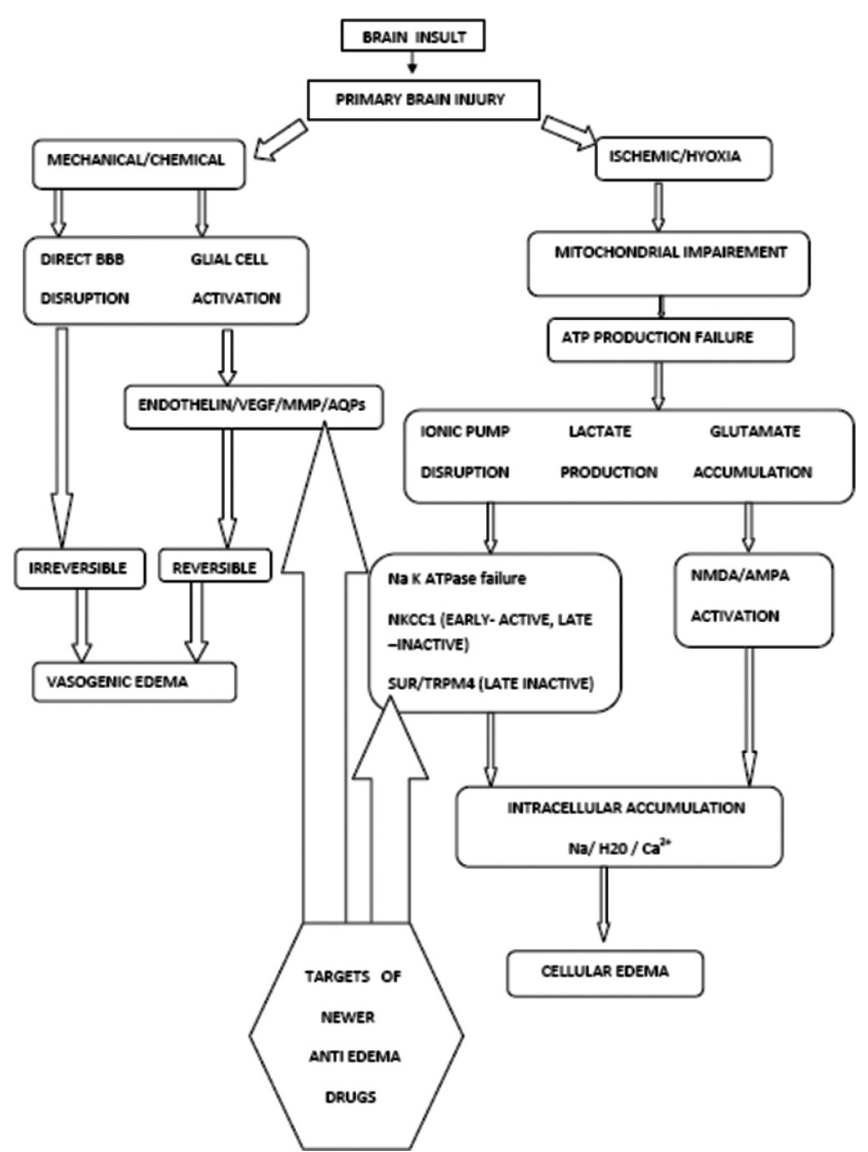

Figure 1: Depiction of pathophysiological mechanisms of cerebral oedema

is surrounded by penumbra zone where blood flow if restored within certain time limits $(3 \mathrm{~h})$, then the tissue is potentially salvageable.

Excitatory neurotransmitter glutamate is normally released in the synaptic cleft for neurotransmission and then immediately removed by energy dependent uptake pathways. During ischaemia/hypoxia, energy dependent pathways fail and there is accumulation of glutamate to toxic levels which causes abnormal surge of neuronal activity through N-methyl-D-aspartate (NMDA), AMPA, metabotrophic glutamate and high affinity kinate receptors. Out of all these, most important is NMDA receptor which play central role in $\mathrm{Ca}^{2+}$ influx into cytoplasm. Persistently activated NMDA receptor causes gradual, slow but excessive rise in intracellular $\mathrm{Ca}^{2}$ ions. Also, activated AMPA receptors cause $\mathrm{Na}^{+}$dependent depolarisation and further voltage gated $\mathrm{Ca}^{2}$ entry into cells. Hence, during normal and abnormal neuronal activity, there is cotransport of $3 \mathrm{Na}^{+}, 1 \mathrm{Cl}^{-}, 1 \mathrm{H}^{+}$and antiport $1 \mathrm{~K}^{+}$ion per glutamate molecule along with water molecule. Normally, ATP-dependent pumps maintain high concentration of $\mathrm{Ca}^{2+}$ in extracellular space compared to intracellular space. But, during energy depletion, this mechanism also fails. Excess intracellular $\mathrm{Ca}^{2+}$ causes mitochondrial swelling and further ATP 
production gets impaired. Thus, vicious cycle comes into play. Therefore, neuronal and glial cell efforts to maintain ionic homeostasis ultimately fails resulting in cellular oedema and activation of $\mathrm{Ca}^{2+}$ mediated intracellular secondary cascades and free oxygen radical productions and arachidonic acid metabolites. Normally, glucose is anaerobically metabolised into pyruvate and then it enters into Krebs cycle to produce ATPs, but during hypoxia, pyruvate is converted into lactate. High concentration of lactate further causes neuronal injury and promotes cellular swelling. ${ }^{[8]}$

Cellular oedema involves swelling of astrocytes, neurons and dendrites, but astrocytes are more prone to cytotoxic swelling than neurons (astrocytes are 20 times more in number and have ability to swell 5 times their normal size). ${ }^{[9,10]}$ This oedema fluid is protein-free and contains electrolytes.

\section{Interstitial oedema}

This type of oedema is also known as hydrocephalic oedema. During hydrocephalus, intraventricular pressure increases which cause breakdown of ventricular ependymal lining and hence transependymal migration of CSF into extracellular space. ${ }^{[11,12]}$ Common causes include meningitis, subarachnoid haemorrhage, normal pressure hydrocephalus and obstructing mass in relation to ventricular outflow. Here, oedema fluid composition resembles CSF composition.

\section{Osmotic oedema}

This type of oedema is characterised by imbalance of osmolality between serum plasma and brain parenchyma. Here, cellular and BBB integrity is maintained. Conditions which either decrease serum osmolality or increase brain tissue osmolality will produce abnormal osmotic pressure gradient with net flow of fluid into the brain parenchyma. Clinically, most important example is syndrome of in appropriate antidiuretic hormone (SIADH) secretion where serum hypo-osmolality causes osmotic brain oedema. Other example is traumatic brain injury (TBI) where necrotic tissue in contused brain is hyper osmolal and if reperfusion is carried out with isotonic fluid, then it aggravates osmotic oedema. ${ }^{[13]}$ Here, oedema fluid is rich in electrolytes.

\section{CLINICAL PRESENTATION}

Monro-kellie doctrine states that skull is a closed space with fixed volume and whenever there is increase in one component, brain tries to compensate by decreasing other component but to limited extent (CSF translocation or decrease in blood volume) ${ }^{[14]}$ Cerebral oedema does not cause clinical features until it reaches to stage where brain compensatory mechanism fails and rise in ICP occur. Thus, clinical presentation is secondary to raised ICP, mass effects and cerebral ischemia. Clinical features are non-specific and have varied presentation. These features may include headache, projectile vomiting, lethargy, altered level of sensorium, cranial nerve palsies (abducent nerve palsy-false localising sign), extensor plantar, hypertension, bradycardia, altered respiratory pattern, ultimately coma and death.

\section{RADIOLOGICAL FEATURES}

The initial investigation of choice to investigate cerebral oedema is a computer tomography (CT) scan. On CT scan, cerebral oedema is recognised as an area of hypodensity or hypoattenuation or lucency relative to normal brain parenchyma. In addition, features of mass effects - midline shift, compressed ventricles, sulcal and basal cistern effacement and herniation are seen. The differentiation of types of oedema is done with the help of different sequences acquired through magnetic resonance imaging (MRI). On MRI, cerebral oedema appears as bright signal on T2-weighted image and low signal on T1-weighted image. T1 with contrast helps to delineate the lesion with surrounding oedema (oedema does not enhance with contrast). Fluid attenuated inverse ratio (FLAIR) sequences visualise periventricular signal abnormalities (interstitial oedema) by suppressing signal from CSF [Figures 2-4]. Diffusion weighted and apparent diffusion coefficient sequences help to differentiate cytotoxic and vasogenic/interstitial oedema [Figure 3]. ${ }^{[15]}$ The interstitial/hydrocephalic oedema is characteristically seen as periventricular white matter lucency on FLAIR in MRI sequence [Figure 4].

\section{MANAGEMENT OF CEREBRAL OEDEMA}

Following cerebral injury, consequences of cerebral oedema lead to unnecessary prolong hospital stay and add to mortality. Thus, it is imperative to treat cerebral oedema. Available treatment modalities involve step-wise algorithmic approach. It starts with general measures (optimal head and neck position, adequate oxygenation and maintenance of normotension) to specific interventions (short term hyperventilation, use of osmotic agents, diuretics and corticosteroids). Mannitol and hypertonic saline form the basis of osmotherapy. ${ }^{[16,17]}$ These agents draw fluid into the intravascular space via an osmotic gradient. If all these measures fail, then last resort is decompressive craniectomy, high dose barbiturates (cerebral metabolic suppression) and decompressive laparotomy (severe TBI + inhibitor of apoptosis protein $>20 \mathrm{~mm} \mathrm{Hg}$ ). Currently available treatment modalities either remove oedema fluid by osmotherapy or accommodate oedema fluid by decreasing cerebral blood volume. None of the available treatment modalities target oedema formation. With 

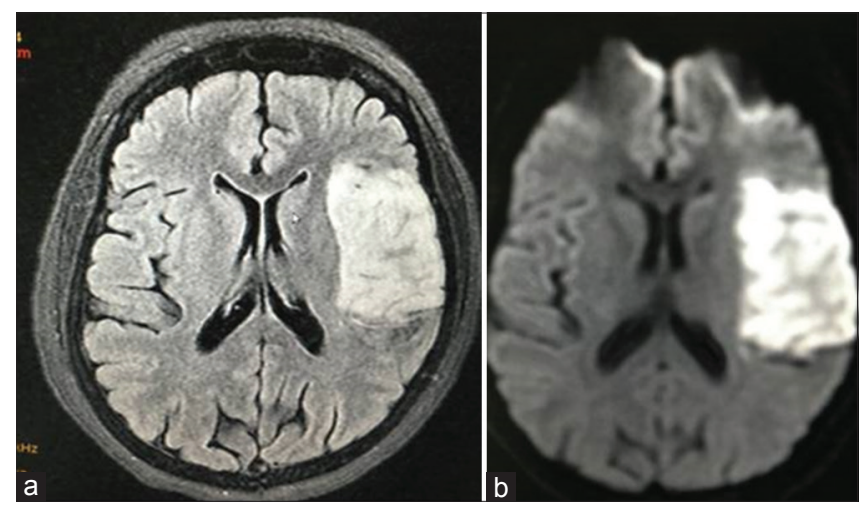

Figure 2: (a) Magnetic resonance (post-contrast) image showing nodular enhancing lesion in left frontal lobe. (b) Magnetic resonance-fluid attenuated inverse ratio image showing perilesional oedema suggestive of vasogenic oedema
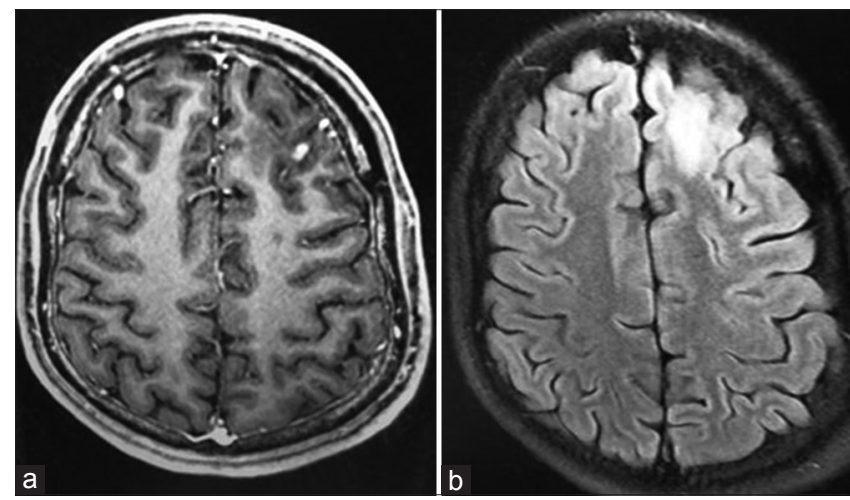

Figure 3: (a) Magnetic resonance-fluid attenuated inverse ratio image showing hyperintense lesion in left frontotemporal region. (b) Magnetic resonance diffusion weighted imaging showing hyperintense signal in left frontotemporal region (diffusion restriction) suggestive of cytotoxic oedema

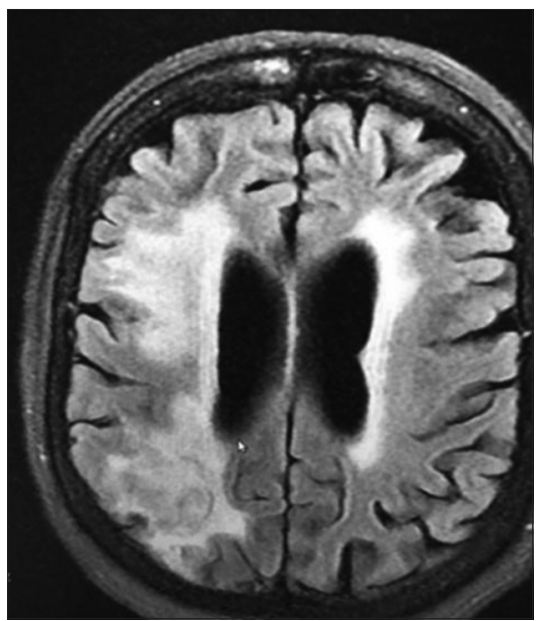

Figure 4: Magnetic resonance fluid attenuated inverse ratio image showing hydrocephalic oedema (periventricular hyperintensity)

advancement in research field, some targets are identified at molecular level which helps in the oedema formation.

\section{EXPERIMENTAL THERAPIES FOR CEREBRAL OEDEMA}

In the last two decades, lot of emphasis have been placed for the search drugs which help in the prevention of oedema fluid formation as well as resolution of already formed oedema. Various mediators involved either in the formation or aggravation of cerebral oedema are identified. These mediators are arachidonic acid, bradykinins, $\mathrm{Ca}^{2+}$, glutamate, free oxygen radicals etc. Modulations of some of these mediators were found useful in the experimental studies but clinically no beneficial effects or unacceptable side effects were seen. In this section, we will discuss anti-oedema drugs with promising results in animal studies.

\section{NKCC1 ANTAGONISTS}

NKCC1 is an intrinsic membrane protein seen at various sites in central nervous system (CNS) such as luminal surface of endothelial cells, neurons, glial and choroid plexus. ${ }^{[18]}$ The primary function is transportation of $\mathrm{Na}^{+}, \mathrm{K}^{+}, \mathrm{Cl}^{-}$ions into cells $\left(1 \mathrm{Na}^{+}: 1 \mathrm{~K}^{+}: 2 \mathrm{Cl}^{-}\right) \cdot{ }^{[19]}$ To maintain electrical neutrality, Na-K-ATPase pump present on albuminal surface move sodium into extracellular space. In animal model, it was found that during brain insult there is upregulation of NKCC1 cotransporter secondary to increased potassium, glutamate levels (in cortical neurons) and cytokines interleukin-6 (capillaries). Since it is secondary, active transporter energy is provided by ATP for its smooth functioning; hence its increased activity is seen during early stages of ischaemia and during reperfusion phase. Bumetanide is known as high efficacy diuretic which belongs to sulfamoyl group. ${ }^{[20]}$ Small size molecule of bumetanide and its good lipid solubility confers an ability to cross BBB. In CNS, it acts as NKCC1 inhibitor at low dose without causing diuresis. ${ }^{[21]}$ Thus, these properties are utilised in various studies to assess its role in the treatment of various neurological diseases such as trauma, ${ }^{[22]} \mathrm{TBI}^{[23,24]}$ and stroke (ischaemic/haemorrhagic). ${ }^{[25]}$ Role of another diuretic agent torsemide in decreasing cerebral oedema through NKCClinhibitor was also studied. ${ }^{[26]}$

\section{SULFONYL UREA RECEPTOR 1/TRANSIENT RECEPTOR POTENTIAL MELASTATIN 4 CHANNEL INHIBITORS}

Sulfonyl Urea Receptor 1/Transient Receptor Potential Melastatin 4 (SUR1/TRPM4) is a non-selective monovalent cation channel with two important features. ${ }^{[27]}$ First, it gets activated when intracellular energy is exhausted and second it needs intracellular 
calcium for its opening. Exhausted ATP levels results in the opening of these channels, sodium influx, membrane depolarisation and cytotoxic oedema formation. In animal models, it was found that SUR1/TRPM4 channel is normally not present, but whenever there is ischaemic injury (exhausted ATP levels e.g.: TBI, tumours), they get transcriptionally upregulated. ${ }^{[28]}$ Also, SUR1 is an important part of ATP sensitive K channels. In type 2 diabetics, second generation sulfonylurea inhibitors (glibenclamide) are used as oral hypoglycaemic agents to decrease blood sugar. Glibenclamide act on SUR1 regulatory subunit of ATP sensitive K channels in pancreas. Therefore, role of these drugs in the inhibition of cerebral cytotoxic oedema formation has been studied in animal models. ${ }^{[29]}$ In a rat model of malignant stroke, there was $50 \%$ decreased cerebral oedema formation by glibenclamide and improvement in stroke outcome. ${ }^{[30]}$ Hence, inhibition of this channel can offer new treatment modality to decrease and hence treat cerebral oedema.

\section{VASOPRESSIN RECEPTOR ANTAGONIST}

Various CNS diseases are linked with increased ADH levels. Increased ADH levels in SIADH causes anti diuresis which result in fluid retention and hyponatraemia. If serum sodium level is $<120 \mathrm{mmol} / \mathrm{L}$, there is a decrease in serum osmolality and thus water enters into the brain and results in osmotic oedema. SIADH is commonly associated with aneurysmal subarachnoid haemorrhage where available treatment modalities are fluid restriction, sodium administration either by enteral salt addition or by hypertonic saline, fludrocortisone administration. ${ }^{[31]}$ Since each of these therapies have certain drawbacks, for example, fluid restriction will cause hypovolaemia and hence vasospasm and fludrocortisone causes volume overload with limited role in hyponatraemia, and hypertonic saline is not useful in hypervolaemic hyponatraemia. Normally, there are 2 types of vasopressin receptors present in the body. V1A receptors are present in smooth muscle of vessels while V1B is present in anterior pituitary. V2 receptors are primarily located in renal collecting ducts. It promotes free water reabsorption through cyclic adenosine monophosphate pathway. Conivaptan is a Food and Drug Administration approved vasopressin receptor (V1A/V2) antagonist drug for euvolaemic hyponatraemia correction. ${ }^{[32]}$ Antagonism of V2 receptors promotes water excretion (aquaresis) from the body without affecting serum sodium level. ${ }^{[33]}$ It does not cause any change in blood pressure through V1A receptor antagonism. In various trials, it was found that conivaptan was effective in treating patients with euvolaemic or hypervolaemic hyponatraemia and raise serum sodium level by 6.3 and $9 \mathrm{mmol} / \mathrm{L}$ with daily dose of 40 and $80 \mathrm{mg}$, respectively, in neurocritical care units. ${ }^{[3,35]}$ Very few studies were conducted in brain injured patients with hyponatraemia where drug was found useful in raising serum sodium levels and decreasing raised ICP after single bolus dose. ${ }^{[36]}$

\section{AQUAPORIN4 INHIBITORS AND ACTIVATORS}

Aquaporins (AQPs) 1, 4, 5 and 9 were found to be located in astrocytes in association with ependyma, neurons and blood vessels. ${ }^{[3]}$ But among all, AQP4 is most important bidirectional transmembrane water channel in brain. ${ }^{[38]}$ It acts along with inward rectifying $\mathrm{K}^{+}$channels at astrocytic foot ends. AQP4 modulators play a crucial role in aggravation/resolution of cytotoxic and vasogenic brain oedema. ${ }^{[3,40]}$ Various AQP4 inhibitors (brain protection in cytotoxic oedema) and activators (facilitate oedema fluid clearance in vasogenic and hydrocephalic oedema) have been studied in mice models, ${ }^{[41,42]}$ but their role in humans still need further studies.

\section{MATRIX METALLOPROTEINASE INHIBITORS}

In various rodent models, during vasogenic oedema, matrix metalloproteinase (MMP) inhibitors were used and it was found that they restore BBB integrity in early phase, but not after $48 \mathrm{~h}$. But, they have major drawback that they delayed recovery due to their role in angiogenesis and neurogenesis. ${ }^{[33,44]}$

\section{VASCULAR ENDOTHELIAL GROWTH FACTOR INHIBITORS AND FACILITATORS}

In ischaemic rodent model, administration of vascular endothelial growth factor-A (VEGF) inhibitors or recombinant angiopoietin 1 decreased BBB breakdown whereas VEGF-B facilitators provide protection against BBB breakdown. ${ }^{[45,46]}$ Therefore, they may play role in the treatment of vasogenic oedema.

\section{ENDOTHELIN RECEPTOR TYPE B}

Endothelins are vasoconstrictive peptides which exert their action through receptors - endothelin receptor type A (ETA) and ETB-R. In CNS, ETB-R is present on resting astrocytes. Stimulation of these receptors activate astrocytes which exert their action through production of MMP9 and VEGF-A. ${ }^{[47,48]}$ In mice model, selective ETB-R antagonists such as BQ788 and IRL-2500 attenuated cold injury-induced BBB disruption and vasogenic brain oedema. ${ }^{[49]}$ 


\section{SUMMARY}

Cerebral oedema, irrespective of its type, is potentially devastating consequence of brain injury with significant morbidity and mortality. The primary brain insult either alter membrane permeability (BBB and neuroglial) or cause ionic disruption or both which ultimately result in perturbation of brain fluid homeostasis. Disturbances in the brain fluid homeostasis result in grave consequences due to rigid bony calvarias. Treatment of cerebral oedema currently resides in primitive era with only symptomatic management. In experimental animal models, various mediators and newer ion channels were found to play significant role in the pathogenesis of cerebral oedema. Pharmacological modulation of new ion channels and mediators helps in prevention and resolution of cerebral oedema in animal models. These innovations in research help in understanding complex molecular mechanism in cerebral oedema formation and provide new horizons in newer anti-oedema treatment modalities. However, the challenge lies in translating this advancement from animal models to clinical settings.

\section{Financial support and sponsorship \\ Nil.}

\section{Conflicts of interest}

There are no conflicts of interest.

\section{REFERENCES}

1. Reichardt M. Zur entstehung des hirndrucks. Deutsch Z Nervenheilkd 1905;28:306.

2. Klatzo I. Presidental address. Neuropathological aspects of brain edema. J Neuropathol Exp Neurol 1967;26:1-14.

3. Fishman RA. Brain edema. N Engl J Med 1975;293:706-11.

4. Møllgård K, Saunders NR. The development of the human blood-brain and blood-CSF barriers. Neuropathol Appl Neurobiol 1986;12:337-58.

5. Betz AL, Iannotti F, Hoff JT. Brain edema: A classification based on blood-brain barrier integrity. Cerebrovasc Brain Metab Rev 1989;1:133-54.

6. Kuroiwa T, Miyasaka N, Fengyo Z, Yamada I, Nakane M, Nagaoka $\mathrm{T}$, et al. Experimental ischemic brain edema: Morphological and magnetic resonance imaging findings. Neurosurg Focus 2007;22:E11.

7. Wasterlain CG, Posner JB. Cerebral edema in water intoxication. I. Clinical and chemical observations. Arch Neurol 1968;19:71-8.

8. Arundine $\mathrm{M}$, Tymianski $\mathrm{M}$. Molecular mechanisms of glutamate-dependent neurodegeneration in ischemia and traumatic brain injury. Cell Mol Life Sci 2004;61:657-68.

9. Barron KD, Dentinger MP, Kimelberg HK, Nelson LR, Bourke RS, Keegan S, et al. Ultrastructural features of a brain injury model in cat. I. Vascular and neuroglial changes and the prevention of astroglial swelling by a fluorenyl (aryloxy) alkanoic acid derivative (L-644,711). Acta Neuropathol 1988;75:295-307.

10. Kimelberg HK. Current concepts of brain edema. Review of laboratory investigations. J Neurosurg 1995;83:1051-9.

11. Milhorat TH, Clark RG, Hammock MK. Experimental hydrocephalus. 2. Gross pathological findings in acute and subacute obstructive hydrocephalus in the dog and monkey. J Neurosurg 1970;32:390-9.

12. Milhorat TH, Clark RG, Hammock MK, McGrath PP. Structural, ultrastructural, and permeability changes in the ependyma and surrounding brain favoring equilibration in progressive hydrocephalus. Arch Neurol 1970;22:397-407.

13. Katayama Y, Kawamata T. Edema fluid accumulation within necrotic brain tissue as a cause of the mass effect of cerebral contusion in head trauma patients. Acta Neurochir Suppl 2003;86:323-7.

14. Mokri B. The Monro-Kellie hypothesis: Applications in CSF volume depletion. Neurology 2001;56:1746-8.

15. Loubinoux I, Volk A, Borredon J, Guirimand S, Tiffon B, Seylaz J, et al. Spreading of vasogenic edema and cytotoxic edema assessed by quantitative diffusion and T2 magnetic resonance imaging. Stroke 1997;28:419-26.

16. Cruz J, Minoja G, Okuchi K, Facco E. Successful use of the new high-dose mannitol treatment in patients with Glasgow Coma Scale scores of 3 and bilateral abnormal pupillary widening: A randomized trial. J Neurosurg 2004;100:376-83.

17. Qureshi AI, Suarez JI. Use of hypertonic saline solutions in treatment of cerebral edema and intracranial hypertension. Crit Care Med 2000;28:3301-13.

18. Plotkin MD, Kaplan MR, Peterson LN, Gullan SR, Hebert SC, Delpire E. Expression of the $\mathrm{Na}-\mathrm{K}-2 \mathrm{Cl}$ co transporter BSC2 in the nervous system. Am J Physiol 1997;272:C173-83.

19. Payne JA, Xu JC, Haas M, Lytle CY, Ward D, Forbush B $3^{\text {rd }}$. Primary structure, functional expression, and chromosomal localization of the bumetanide-sensitive $\mathrm{Na}-\mathrm{K}-\mathrm{Cl}$ cotransporter in human colon. J Biol Chem 1995;270:17977-85.

20. Asbury MJ, Gatenby PB, O'Sullivan S, Bourke E. Bumetanide: Potent new "loop" diuretic. Br Med J 1972;1:211-3.

21. Staley KJ. Wrong-way chloride transport: Is it a treatable cause of some intractable seizures? Epilepsy Curr 2006;6:124-7.

22. HaasBR,SontheimerH.Inhibitionofthesodium-potassium-chloride cotransporter isoform-1 reduces glioma invasion. Cancer Res 2010;70:5597-606.

23. Lu KT, Wu CY, Yen HH, Peng JH, Wang CL, Yang YL. Bumetanide administration attenuated traumatic brain injury through IL-1 overexpression. Neurol Res 2007;29:404-9.

24. Simard JM, Chen M, Tarasov KV, Bhatta S, Ivanova S, Melnitchenko L, et al. Newly expressed SUR1-regulated $\mathrm{NC}(\mathrm{Ca}-\mathrm{ATP})$ channel mediates cerebral edema after ischemic stroke. Nat Med 2006;12:433-40.

25. Chen H, Luo J, Kintner DB, Shull GE, Sun D. Na(+)-dependent chloride transporter (NKCC1)-null mice exhibit less gray and white matter damage after focal cerebral ischemia. J Cereb Blood Flow Metab 2005;25:54-66.

26. Staub F, Stoffel M, Berger S, Eriskat J, Baethmann A. Treatment of vasogenic brain edema with the novel $\mathrm{Cl}$ - transport inhibitor torasemide. J Neurotrauma 1994;11:679-90.

27. Chen M, Simard JM. Cell swelling and a nonselective cation channel regulated by internal $\mathrm{Ca} 2+$ and ATP in native reactive astrocytes from adult rat brain. J Neurosci 2001;21:6512-21.

28. Simard JM, Woo SK, Schwartzbauer GT, Gerzanich V. Sulfonylurea receptor 1 in central nervous system injury: A focused review. J Cereb Blood Flow Metab 2012;32:1699-717.

29. Zweckberger $\mathrm{K}$, Hackenberg $\mathrm{K}$, Jung CS, Hertle DN, Kiening KL, Unterberg AW, et al. Glibenclamide reduces secondary brain damage after experimental traumatic brain injury. Neuroscience 2014;272:199-206.

30. Simard JM, Tsymbalyuk N, Tsymbalyuk O, Ivanova S, Yurovsky V, Gerzanich V. Glibenclamide is superior to decompressive craniectomy in a rat model of malignant stroke. Stroke 2010;41:531-7.

31. Sherlock M, O'Sullivan E, Agha A, Behan LA, Rawluk D, 
Brennan P, et al. The incidence and pathophysiology of hyponatraemia after subarachnoid haemorrhage. Clin Endocrinol (Oxf) 2006;64:250-4.

32. Cawley MJ. Hyponatremia: Current treatment strategies and the role of vasopressin antagonists. Ann Pharmacother 2007;41:840-50.

33. Palm C, Pistrosch F, Herbrig K, Gross P. Vasopressin antagonists as aquaretic agents for the treatment of hyponatremia. Am J Med 2006;119 7 Suppl 1:S87-92.

34. Murphy T, Dhar R, Diringer M. Conivaptan bolus dosing for the correction of hyponatremia in the neurointensive care unit. Neurocrit Care 2009;11:14-9.

35. Wright WL, Asbury WH, Gilmore JL, Samuels OB. Conivaptan for hyponatremia in the neurocritical care unit. Neurocrit Care 2009; 11:6-13.

36. Galton C, Deem S, Yanez ND, Souter M, Chesnut R, Dagal A, et al. Open-label randomized trial of the safety and efficacy of a single dose conivaptan to raise serum sodium in patients with traumatic brain injury. Neurocrit Care 2011;14:354-60.

37. Papadopoulos MC, Verkman AS. Aquaporin water channels in the nervous system. Nat Rev Neurosci 2013;14:265-77.

38. Papadopoulos MC, Verkman AS. Aquaporin-4 and brain edema. Pediatr Nephrol 2007;22:778-84.

39. Yang B, Zador Z, Verkman AS. Glial cell aquaporin-4 overexpression in transgenic mice accelerates cytotoxic brain swelling. J Biol Chem 2008;283:15280-6.

40. Papadopoulos MC, Manley GT, Krishna S, Verkman AS. Aquaporin-4 facilitates reabsorption of excess fluid in vasogenic brain edema. FASEB J 2004;18:1291-3.

41. Igarashi $\mathrm{H}$, Huber VJ, Tsujita M, Nakada T. Pretreatment with a novel aquaporin 4 inhibitor, TGN-020, significantly reduces ischemic cerebral edema. Neurol Sci 2011;32:113-6.
42. Bhattacharya P, Pandey AK, Paul S, Patnaik R, YavagalDR.Aquaporin-4inhibition mediates piroxicam-induced neuroprotection against focal cerebral ischemia/reperfusion injury in rodents. PLoS One 2013;8:e73481.

43. Shigemori $Y$, Katayama $Y$, Mori $T$, Maeda $T$, Kawamata $T$. Matrix metalloproteinase- 9 is associated with blood-brain barrier opening and brain edema formation after cortical contusion in rats. Acta Neurochir Suppl 2006;96:130-3.

44. Sood RR, Taheri S, Candelario-Jalil E, Estrada EY, Rosenberg GA. Early beneficial effect of matrix metalloproteinase inhibition on blood-brain barrier permeability as measured by magnetic resonance imaging countered by impaired long-term recovery after stroke in rat brain.J Cereb Blood Flow Metab 2008;28:431-8.

45. Jiang S, Xia R, Jiang Y, Wang L, Gao F. Vascular endothelial growth factors enhance the permeability of the mouse blood-brain barrier. PLoS One 2014;9:e86407.

46. Koyama J, Miyake S, Sasayama T, Kondoh T, Kohmura E. Effect of VEGF receptor antagonist (VGA1155) on brain edema in the rat cold injury model. Kobe J Med Sci 2007;53:199-207.

47. Koyama Y, Tanaka K. Intracerebroventricular administration of an endothelin ETB-receptor agonist increases expression of matrix metalloproteinase- 2 and -9 in rat brain. J Pharmacol Sci 2010;114:433-43.

48. Koyama Y, Nagae R, Tokuyama S, Tanaka K. I.c.v. administration of an endothelin ETB receptor agonist stimulates vascular endothelial growth factor - A production and activates vascular endothelial growth factor receptors in rat brain. Neuroscience 2011;192:689-98.

49. Michinaga S, Nagase M, Matsuyama E, Yamanaka D, Seno N, Fuka M, et al. Amelioration of cold injury-induced cortical brain edema formation by selective endothelin ETB receptor antagonists in mice. PLoS One 2014;9:e102009. 